\title{
Bioarcheology of the Bronze Age Population in the Kumo-Manych Depression (Russia)
}

\author{
Borutskaya Svetlana ${ }^{1,}$, , Vasilyev Sergey ${ }^{2}$ \\ ${ }^{1}$ Biological Faculty, Department of Anthropology, Lomonosov Moscow State University, Moscow, Russia \\ ${ }^{2}$ Centre of Physical Anthropology, Institute Ethnology and Anthropology RAS, Moscow, Russia
}

Email address:

borsbor@yandex.ru (Borutskaya Svetlana), vasbor1@yandex.ru (Vasilyev Sergey)

\section{To cite this article:}

Borutskaya Svetlana, Vasilyev Sergey. Bioarcheology of the Bronze Age Population in the Kumo-Manych Depression (Russia). Earth Sciences. Special Issue: Modern Problems of Geography and Anthropology. Vol. 4, No. 5-1, 2015, pp. 30-34. doi: 10.11648/j.earth.s.2015040501.16

\begin{abstract}
In this work we present a morphological study of postcranial skeletons from the Yamna-culture burials of the following barrow groups: Zunda-Tolga, Manjikiny, Mu-Sharet, Ostrovnoy, which are situated in the right bank of the Manych river in Kalmykia, and Peschany-V, located near the village of Remontnoe in the south of Rostov Oblast. The Yamna culture is the earliest culture of the Bronze Age, which existed in the studied territories in 3300-2350 BC. We also used some finds from the Yamna-culture burials in Rostov Oblast as comparative material. This collection is kept in the Southern Scientific Center of the Russian Academy of Sciences in Rostov-on-Don. The burials were situated in various parts of the Don catchment area within Rostov Oblast (Lower Don region). The skeletal materials were collected by the joint expedition of the State Historical Museum (Moscow) and the Kalmyk Institute of Economic and Legal Research in the territory of the Republic of Kalmykia and in the south of Rostov Oblast. The collection is kept in the archaeological department of the State Historical Museum. We have taken measurements and then calculated various indices of skeletal proportions, as well as robustness and strength indices of limb bones. Variations in values of various indices are presented in works of Y.Y. Roginsky and M.G. Levin and E.N. Khrisanfova. The intravital body length was reconstructed with the use of Bunak, Dupertuis and Hadden formulae. Thus, in terms of limb proportions, intravital body length, some peculiarities of body build and morphology of limb bones, the two series are not completely homogeneous. The common features for the Yamna-culture people from the barrow burials in the territory of the Republic of Kalmykia are: quite long legs, comparatively short tibiae, broad shoulders among males, average or above-the-average intravital body length. All the long arm bones and tibiae were characterized by considerable robustness. The Yamna-culture people from the Lower Don region were also united by comparatively long legs, average correlation between the antebrachium and tibia length, slightly elongated tibiae in relation to femurs. The intravital body length was average or above the average. The individuals were characterized by average or high robustness of humeri, radii, femurs and tibiae.
\end{abstract}

Keywords: Kumo-Manych Depression, Bronze Age, Population, Postcranial Skeletons

\section{Introduction}

In this work we present a morphological study of postcranial skeletons from the Yamna-culture burials of the following barrow groups: Zunda-Tolga, Manjikiny, $\mathrm{Mu}-$ Sharet, Ostrovnoy, which are situated in the right bank of the Manych river in Kalmykia, and Peschany-V, located near the village of Remontnoe in the south of Rostov Oblast. The Yamna culture is the earliest culture of the Bronze Age, which existed in the studied territories in 3,300-2,350 BC. We also used some finds from the Yamna-culture burials in Rostov Oblast as comparative material. This collection is kept in the Southern Scientific Center of the Russian Academy of
Sciences in Rostov-on-Don. The burials were situated in various parts of the Don catchment area within Rostov Oblast (Lower Don region).

The people, who left the Yamna-culture burials in the territory of Kalmykia, were nomadic herdsmen. In the first half of the 3rd millennium $\mathrm{BC}$, the climate was warmer and more humid than nowadays. Mobility of the population was comparatively limited, which was caused, firstly, by the fact that the most productive pastures situated near water wells were free from farmers, and, secondly, herdsmen chose the best pastures for their stock and could stay there for a long time. The valley of the Manych river constituted a pasture mainly in spring-summer period, which is testified by studies of vegetation (above all, blossom dust) and animal remains 
(shells, teeth) from the Yamna-culture burials [1]. The winter pastures of the second half of the 3rd millennium BC were most probably situated in the steppes of Ciscaucasia, which had less severe climate [2].

Almost all human skeletal bones in the Yamna-culture burials in the studied territory were covered with red or brown ocher. The skeletons were in extremely poor condition, and in a number of cases it did not allow us to perform the full-fledged morphological analysis. In the above-mentioned barrow groups, 29 burials belonged to the Yamna culture of the Bronze Age, but only 19 of them (16 male and 3 female ones) were more or less suitable for osteometric study. Other burials contained very fragmented and incomplete skeletons. We often had to reconstruct lengths of bones on the basis of the procedure and tables developed by N.N. Mamonova [3].

According to A.A. Khokhlov, the skulls of the Yamna-culture people from Kalmykia are comparatively homogeneous. In general, both male and female skulls are characterized by large brainpans, meso-brachycrania, straight foreheads, refracted napexes, broad and comparatively low facial sections, very prominent nasal bones, orthognathia and moderate horizontal profiling. These features stay within a previously formed idea concerning specific morphological characteristics of the Yamna-culture craniological series from Kalmykia [4].

\section{Materials and Methods}

The skeletal materials were collected by the joint expedition of the State Historical Museum (Moscow) and the Kalmyk Institute of Economic and Legal Research in the territory of the Republic of Kalmykia and in the south of Rostov Oblast. The collection is kept in the archaeological department of the State Historical Museum.

We have taken measurements and then calculated various indices of skeletal proportions, as well as robustness and strength indices of limb bones. Variations in values of various indices are presented in works of Y.Y. Roginsky and M.G. Levin and E.N. Khrisanfova [5, 6]. The intravital body length was reconstructed with the use of Bunak, Dupertuis and Hadden formulae [7].

\section{Results and Discussions}

In most cases, according to the brachial-femoral index, femurs are moderately or often greatly elongated. At the same time, a male and a female from Mu-Sharet and one individual from Manjikiny show the opposite situation with this index. Perhaps, we can suggest the absence of certain tendencies. The same may be said about the radio-tibial index.

The antebrachium length in relation to brachium is generally average or below the average. However, the respective indices of two female skeletons and the individual from Manjikiny (Barrow 14, Burial 12) are, in contrast, above the average, which corresponds to considerably elongated antebrachium.

Values of the tibial-femoral (crural) index among the
Yamna-culture people from the barrow groups discover a certain tendency: they are slightly below the average, which corresponds to slightly shortened tibiae in relation to femurs.

The male individuals are characterized by average or above-the-average shoulder breadth, the females had narrow shoulders.

The analysis of pelvic indices showed that the combined group included skeletons of males characterized by broad low, broad high and narrow high pelvises, i.e. the group is non-homogeneous in this respect, though we should make allowance for the insufficient number of observations. Almost all the males are characterized by quite broad sacra.

The calculated intravital body length of the male individuals was generally above the average, sometimes quite considerably. The average stature of the males amounted to $174.2 \mathrm{~cm}$. The range of variations was: $166.7-181.4 \mathrm{~cm}$. Moreover, the barrow groups of Manjikiny and Mu-Sharet contained skeletons of the tallest and relatively the shortest males (more properly - those of average height).

The intravital stature of the females was characterized as average, but there were only two observations, which did not allow us to make a statistically correct conclusion.

The Table 1 shows the calculations of skeletal proportion indices for the Yamna-culture people from Rostov Oblast. Altogether, we studied 59 skeletons. 47 of them belonged to males, $8-$ to females and $4-$ to children. The skeletons were in various conditions. In most cases, they were incomplete, many bones and especially skulls were fragmentary. For our osteometric study we were able to use 20 male and 5 female skeletons with bones, which allowed us to take at least the minimal measurements. Some of these findings are published $[8,9,10]$. The table shows average, minimum and maximum values of the proportion indices and the intravital body length for the whole group.

Both males and females were characterized by average or slightly below-the-average correlation between the lengths of upper and lower limbs, which is characteristic for the mid-continent adaptive type. The similar result was obtained for the Yamna-culture people from Kalmykia.

Most of individuals were characterized by the average correlation between the brachium and femur lengths. But two males from the burial site Vorotilov I and a male from the burial site Zakatny II had elongated brachii. In terms of this index, there is no similarity with the Yamna-culture people from Kalmykia, and we can even trace the opposite tendency.

The correlation between the antebrachium and tibia lengths is generally close to average values for modern man. Only an individual from the burial site Vorotilov I (Barrow 1, Burial 11) had a clearly shortened antebrachium.

The brachial or radio-brachial indices of most Yamna-culture individuals from this region suggest the average correlation between the antebrachium and brachium lengths and - even a little more often - slightly elongated antebrachium. The only exception is a male from the burial site Vorotilov I (Barrow 1, Burial 7), who has a clearly shortened antebrachium. The Yamna-culture people from Kalmykia, in contrast, have shortened antebrachii in relation 
to brachii.

The crural index shows us the correlation between the tibia and femur lengths. In this group, these values are average and above the average. In most cases, the indices are indicative of relatively elongated tibiae of males. The similar result was obtained for the Yamna-culture people from Kalmykia. Even more often, the tibiae were elongated.

The absolute and relative shoulder breadths of the Yamna-culture people from Rostov Oblast showed no similarity. The Table 1 demonstrates a wide range of variations for these skeletal indices. A male from the burial site Zakatny II (Excavation site 2, Square 9, Burial 12) had especially narrow shoulders - slightly less than $31 \mathrm{~cm}$. The Yamna-culture males from the North Caspian sea region had broader shoulders than the ones from Rostov Oblast.

The data about the pelvis breadth are scarce - we managed to measure this skeletal index only for two male individuals. The absolute values correspond to the pelvis of average size. The pelvic index suggests the low pelvis. Comparison with the individuals from Kalmykia does not make sense.

The sacral index was specified only for three male skeletons. The Table 1 shows the great difference between individuals: one of them had quite a narrow sacrum (subplaticheric), two others - wide, platicheric one. At the same time, the sacral index of an individual from the burial site Vorotilov I (Barrow 1 , Burial 18), which equals to 140 , suggests a very broad sacrum.

In order to specify the intravital body length (stature), we used the formulae devised by Bunak, Pearson and Lee, Dupertuis and Hadden (Alekseyev, 1966). The Yamna-culture males show the considerable range of variations - from below-the-average - $164.3 \mathrm{~cm}$ (Zakatny II, Excavation site 2, Square 9, Burial 12) to tall ones $-179.8 \mathrm{~cm}$ (Vorotilov I, Barrow 1, Burial 11). The difference between the minimum and maximum values is $15.5 \mathrm{~cm}$. Meanwhile, the values of body length represent quite a uniform sequence. In general, we can say that the Yamna-culture males from the territory of Rostov Oblast were characterized by the average or above-the-average stature. The females were characterized by the average stature (however, the available data are very scarce).

It is interesting to note that the exact same result was obtained, while we were studying the reconstructed intravital body length of the Yamna-culture males and females from the territory of the Republic of Kalmykia, where the body length of males varied within the range of $167-181 \mathrm{~cm}$, without any regularities between burial sites. The intravital body length of females was also described as average.

Most of skeletons were characterized by claviculae of average or increased robusticity. The same may be said about robustness of humeri and ulnae. The radii are distinguished by high robustness and considerable flatness of shafts. Flatness of the ulnae diaphysis in their upper parts is various (more often - increased).

Robusticity of femur shafts is also various, irrespective of barrow groups. A male from the Burial 1 in the Barrow 16 of the barrow group Manjikiny-2 had super-robust femurs and other long bones. Flatness of shaft in the middle part of femur and development of posterior pilaster are different for various individuals - we could not trace any tendencies in this respect. In some cases, definitive conclusions cannot be made due to the scarcity of sample collections. Platimetry of femurs, which corresponds to strength of the upper part of diaphysis, is also various: from low to high. The skeletons from the barrow group Manjikiny are characterized by average or high strength of femur in its upper section.

Robustness of tibiae of all the skeletons from all the burial sites is high or super-high. Flatness of shafts in the middle part is average or considerable. Platicnemy (flatness of bones at the level of nutrient foramen) of the tibiae is various - there are both saber-form (flattened) and eurecnemic (expanded) bones; the scarcity of skeletons did not allow us to reveal any tendencies.

The only female skeleton from the barrow group $\mathrm{Mu}$-Sharet, for which we could calculate the discussed indices, was characterized by average robustness of claviculae and ulnae, above-the-average robustness of humeri, radii and tibiae, sufficient gracility and poor strength of femurs. Moreover, we can state considerable flatness of the radii and ulnae and, by contrast, eurecnimicity of the tibiae. However, these conclusions do not characterize female skeletons of the whole population.

Thus, there are no evident differences in the proportion indices and robustness of individuals from various barrow groups. We can note that, according to our data, most of the Yamna-culture males from the North Caspian sea region were generally characterized by average or reduced values of the intermembral index, shortened tibiae in relation to the length of femurs, average or broad shoulders, average or high robustness of skeletons and quite tall stature. The data for female skeletons are too scarce to make any conclusions.

The males and females have various robustness of claviculae. There is a range of variations from very gracile to very robust claviculae. In contrast to the Yamna-culture people from the Low Don region, the individuals from Kalmykia were distinguished by the claviculae of average or increased robustness, or, rather, that group demonstrated such a tendency.

The humeri are generally of average robusticity, with quite well pronounced bone base of deltoid asperity. In general, the humeri of individuals from Kalmykia are more robust.

The radii of all the individuals are of average robustness or robust. Meanwhile, the transverse development of bone shafts is unexceptionally much more pronounced than the sagittal one. In other words, the bones are very flattened. The exact same regularity in the morphology of radii was revealed, while we were studying the skeletons of the Yamna-culture people from the barrows in the territory of Kalmykia and in the south of Rostov Oblast.

The ulnae are of average robustness, and only an extant left bone of a male from the burial site Cherny II (Barrow 5, Burial 2 ) is very gracile. The ulnae of individuals are characterized by low flatness of shaft in its middle part and by sufficient strength in the upper section of diaphysis (the bones are plato- 
or eurolenic). The ulnae of the Yamna-culture people from Kalmykia are a little more robust, though in general they are similar to those of the Yamna-culture people from Rostov Oblast.

Robusticity of the femurs is average or above the average. The remarkable exception is the only extant left femur from a female's burial. The pilastry index of both males and females is quite low and corresponds to poor or quite poor sagittal development of bones and, therefore, to pronouncement of the posterior pilaster - the bone base of linea aspera. The platimetry indices of femurs are also quite low. They correspond to hyperplatimetric or platimetric bones, i.e. those, which are very flattened in the upper part of diaphysis, even despite quite pronounced gluteal asperity. Such femurs cannot be regarded as very strong in the respective section. In general, the group of the Yamna-culture people from the Lower Don region show certain tendencies in the specific features of their femurs, as distinguished from the Yamna-culture people from Kalmykia and the south of Rostov Oblast.

The tibiae of males are described as of average robusticity or robust, especially in the middle part of diaphysis, those of females - as gracile. The flatness of bones at the level of nutrient foramen (i.e. above) is represented by two opposite variants: some bones are platicnemic (flattened in saber form) or eurecnemic (i.e. expanded). These two opposites are also observed for two females with specified platicnemy index. The strengths of tibiae of the Yamna-culture people from Rostov Oblast and Kalmykia are almost similar: both are characterized by robustness and even increased robusticity of bones.

\section{Conclusions}

Thus, in terms of limb proportions, intravital body length, some peculiarities of body build and morphology of limb bones, the two series are not completely homogeneous. The common features for the Yamna-culture people from the barrow burials in the territory of the Republic of Kalmykia are: quite long legs, comparatively short tibiae, broad shoulders among males, average or above-the-average intravital body length. All the long arm bones and tibiae were characterized by considerable robustness.

The Yamna-culture people from the Lower Don region were also united by comparatively long legs, average correlation between the antebrachium and tibia length, slightly elongated tibiae in relation to femurs. The intravital body length was average or above the average. The individuals were characterized by average or high robustness of humeri, radii, femurs and tibiae.

Table 1. Calculations of limb proportion indices for Yamna-culture people from the Lower Don region (Rostov Oblast).

\begin{tabular}{|c|c|c|c|c|c|c|c|c|}
\hline Indices & $\mathbf{n}$ & $\mathbf{X}$ & $\min$ & $\max$ & $\mathbf{n}$ & $\mathbf{X}$ & Min & $\max$ \\
\hline Males & & & & & \multicolumn{4}{|c|}{ Females } \\
\hline Intermembral & 8 & 69.27 & 67.03 & 71.65 & 1 & 68.18 & & \\
\hline Brachial-femoral & 10 & 71.51 & 67.90 & 74.61 & 1 & 70.38 & & \\
\hline Radio-brachial & 10 & 77.22 & 72.67 & 78.83 & 1 & 76.26 & & \\
\hline Tibial-femoral & 10 & 82.31 & 79.52 & 85.66 & 2 & 80.59 & 79.22 & 81.95 \\
\hline Clavicular-brachial & 8 & 45.88 & 41.59 & 51.10 & 1 & 45.58 & & \\
\hline
\end{tabular}

The Yamna-culture people from Kalmykia and Rostov Oblast turned out to be similar in terms of their intravital body length, comparatively long legs and shortened tibiae. In general, the Yamna-culture population from the territory of the Republic of Kalmykia was distinguished by higher robustness of postcranial skeleton bones.

\section{Acknowledgements}

We are grateful for financial support by RFBR, grant № 14-06-00442a.

\section{References}

[1] Kirillova I.V., Gol'yeva A.A., Klevezal' G.A., Mikhaylov K.E., Trunova Y.E., Shishlina N.I. Combined method for determining season of making interments of the bronze age of Kalmykia. In the book: Seasonal economic cycle of the population of North-Western Caspian region in the bronze age. Moscow, 2000. In Russian.

[2] Khibert F.T. The origin of the steppe herding: mobile lifestyle of the population and the definition of season of archaeological sites. Construction of models and scientific analysis. In the book: Seasonal economic cycle of the population of North-Western Caspian region in the bronze age. Moscow, 2000. In Russian.

[3] Mamonova N.N. Determination of the length of the bones in part. // Questions of anthropology, 1968, vol.29.

[4] Khokhlov A.A., Borutskaya S.B. The paleoanthropological analysis of the burials of the bronze age barrow group Manjikani of the Republic of Kalmykia. // "Ecology and demography of human rights in past and present". Third anthropological reading of the 75-th anniversary of the birth of academician V. P. Alekseev. November 15-17, 2004, Moscow. Abstract. In Russian.

[5] Roginsky Y.Y., Levin M.G. Anthropology. Moscow, 1978. In Russian.

[6] Khrisanfova E.N. Evolutionary morphology of the human skeleton. Moscow, 1978. In Russian.

[7] Alekseyev V.P. Osteometry. Moscow, 1966. In Russian.

[8] Borutskaya S.B., Afanasyeva A.O. Osteological and paleopathological study of the population of the Yamna culture of the bronze age of the Rostov region. Herald of anthropology. Scientific almanakh. Vol.17, 2009. In Russian. 
34 Borutskaya Svetlana and Vasilyev Sergey: Bioarcheology of the Bronze Age Population in the Kumo-Manych Depression (Russia)

[9] Borutskaya S. B., Afanasieva A. O., Vasilyev S. V. Comparative analysis of the osteology of the population in the early bronze age of the Northern Caspian and the Lower Don region // "Interaction of cultures of the peoples of the Caspian region", Elista, Izd-vo KGU, 2011. P. 42-50. In Rusian.
[10] Vasilyev S.V., Turin R.A., Borutskaya S.B., Ricerca paleoantropologica bronze age popolazione media podonja. // Italian Science Review. 2014; 4(13). PP. 95-97. In Italian. 